\title{
Heat transfer characteristics of MWCNT nanofluid in rectangular mini channels
}

\author{
Asif Afzal*, A.D. Mohammed Samee, R.K. Abdul Razak, M.K. Ramis \\ Department of Mechanical Engineering, P. A. College of Engineering (Affiliated to Visvesvaraya Technological University), \\ Mangaluru, India
}

Corresponding Author Email: asif.afzal86@gmail.com

https://doi.org/10.18280/ijht.360130

Received: 29 October 2017

Accepted: 05 March 2018

\section{Keywords:}

MWCNT, water, nanofluid, rectangular minichannels, thermal analysis.

\begin{abstract}
This paper presents an experimental comparative thermal analysis of Multi Walled Carbon Nano Tubes (MWCNT) in rectangular minichannels. $0.01 \%$ volume concentration of MWCNT nanoparticles were suspended in water as base fluid to obtain MWCNT-water nanofluid. MWCNT nanoparticles do not readily get mix well with water, hence functionalization of these particles is carried out. Scanning Electron Microscopy (SEM) analysis is done for the functionalized MWCNT nanofluid. For $0.251 \mathrm{pm}$ (liter per minute), $0.51 \mathrm{pm}$ and $0.75 \mathrm{lpm}$ flow rates variation in Nusselt number $(\mathrm{Nu})$, Convective heat transfer coefficient $(h)$, friction factor, pressure drop and pumping power for MWCNT-water nanofluid is compared with water. For all the flow rates considered in present investigation, an increase in all the thermal performance parameters is observed. For 0.5lpm flow rate of nanofluid, the \% enhancement in Convective heat transfer coefficient and actual heat transfer rate is 15.48 and 91.21 which is maximum compared to other flow rates considered in the present investigation.
\end{abstract}

\section{INTRODUCTION}

Minichannels heat sink serves as a means of cooling for several devices. Due to this, attention of researchers is increasing for their application in automobile, aerospace, bioengineering, refrigeration and electronic cooling [17-18]. To enhance the heat transfer phenomenon in minichannels, nanoparticles are mixed with conventional fluids like water and circulated through the channels. The obtained nanofluid is passed through the minichannels which results in great enhancement of heat transfer rate [19-20]. Many nanofluids prepared using nanoparticles like $\mathrm{Al}_{2} \mathrm{O}_{3}, \mathrm{CuO}, \mathrm{TiO}_{2}, \mathrm{SiO}_{2}$, MWCNT etc., are studied by various researchers for their application in different heat sinks and heat exchangers $[7,21$, 22], [23-25], [26]. The other type of heat sink is microchannel, but there is large pressure drop compared to minichannels which leads to high pumping power requirement. Minichannels of up to $3 \mathrm{~mm}$ hydraulic diameter are suggested as more suitable for high heat flux and less drop in pressure

\section{[20, 27].}

Many investigations on minichannels using different nanofluids are carried out in the recent past. In Table 1, the type of nanoparticles used, type of equipment employed for heat transfer study, volume concentrations (VC) and enhancement obtained by various experimental or numerical investigations are presented.

From the summary presented in the Table 1 it is clearly understood that a variety of nanofluids for rectangular, circular and trapezoidal type of minichannels are adopted for thermal investigation. Few others have also used alumina-water [28], alumina aqueous solution [29], $\mathrm{Al}_{2} \mathrm{O}_{3}$-ethylene glycol [11], MWCNT-water in circular tube [30] for their research. However, no work is reported on comparative thermal analysis of MWCNT-water nanofluid in rectangular minichannels. Hence, the present experimental investigation is intended to study a comparative thermal performance of rectangular minichannels subjected to MWCNT nanofluid and water.

Table 1. Summary of research done in minichannels for thermal analysis of nanofluids

\begin{tabular}{|c|c|c|c|c|c|}
\hline $\begin{array}{c}\text { Nanoparticles } \\
\text { used }\end{array}$ & Base fluid & $\begin{array}{l}\text { Type of } \\
\text { channel }\end{array}$ & $\begin{array}{c}\text { Parameters/nano } \\
\text { particles } \\
\text { concentration }\end{array}$ & Results & Reference \\
\hline $\mathrm{Al}_{2} \mathrm{O}_{3}$ & Water & minichannel & $0.1-0.25 \% \mathrm{VC}$ & $\begin{array}{l}18 \% \text { improvement in convective heat } \\
\text { transfer coefficient }(\mathrm{h})\end{array}$ & [1] \\
\hline $\mathrm{Al}_{2} \mathrm{O}_{3}$ and $\mathrm{TiO}_{2}$ & Water & minichannel & $0.8-4 \% \mathrm{VC}$ & $17.3 \%$ and $16.5 \%$ in cooling & [2] \\
\hline $\mathrm{TiO}_{2}$ and $\mathrm{SiC}$ & Water & minichannel & $0.8-4 \% \mathrm{VC}$ & $h$ improved & [3] \\
\hline $\mathrm{Al}_{2} \mathrm{O}_{3}$ & Water & minichannel & 0.1 and $0.2 \% \mathrm{VC}$ & $23.92 \%$ in local $\mathrm{Nu}$ & \\
\hline & Water & Rectangular & $\begin{array}{c}\text { Channel height \& } \\
\text { width }\end{array}$ & improved actual heat transfer rate & [4] \\
\hline $\mathrm{Al}_{2} \mathrm{O}_{3}$ and $\mathrm{TiO}_{2}$ & Water & Rectangular & $4 \% \mathrm{VC}$ & $11.98 \%$ \& $9.397 \%$ improvement of TC & [2] \\
\hline $\mathrm{Al}_{2} \mathrm{O}_{3}$ & Water & Rectangular & $\operatorname{Re} 133$ to 1515 & $h$ improved & [5] \\
\hline
\end{tabular}




\begin{tabular}{|c|c|c|c|c|c|}
\hline & Water & $\begin{array}{l}\text { Straight, } \\
\text { diamond\& } \\
\text { offset }\end{array}$ & $\operatorname{Re} 17$ to 450 & $\mathrm{Nu}$ linearly varies with $R e$ & [6] \\
\hline & R245fa & Pin \&strip fin & $\begin{array}{l}\text { mass flow rate and } \\
\text { heat flux }\end{array}$ & more suitable for hot-spot cooling & [7] \\
\hline & Water & $\begin{array}{l}\text { Circular } \\
\text { straight }\end{array}$ & $\begin{array}{l}\operatorname{Re} 200 \text { to } 900, \\
\text { oblique fin }\end{array}$ & $\mathrm{Nu}$ variation is from $-5.8 \%$ to $7.0 \%$ & {$[8]$} \\
\hline $\mathrm{TiO}_{2}$ & Water & Rectangular & $R e$, heat flux & Enhanced heat transfer rate & [9] \\
\hline $\begin{array}{c}\text { Diamond, } \mathrm{CuO}, \\
\mathrm{SiO}_{2}\end{array}$ & & wavy & $\begin{array}{l}\text { amplitude, } \\
\text { wavelength, VC }\end{array}$ & better cooling performance & {$[10]$} \\
\hline $\mathrm{Al}_{2} \mathrm{O}_{3}$ & $\begin{array}{c}\text { water/ethylene } \\
\text { glycol }\end{array}$ & Rectangular & $0.1 \& 0.5 \% \mathrm{VC}$ & $h$ improved up to $23 \%$ & [11] \\
\hline \multirow[t]{2}{*}{$\mathrm{Al}_{2} \mathrm{O}_{3}$ and $\mathrm{TiO}_{2}$} & Water & $\begin{array}{c}\text { U-shaped } \\
\text { mini/micro/m } \\
\text { acrochannels }\end{array}$ & $\operatorname{Re} 125-20000$ & heat transfer increases upto $71 \%$ & [12] \\
\hline & Water & $\begin{array}{l}\text { Rectangular } \\
\text { mini- and } \\
\text { microchannel }\end{array}$ & $\begin{array}{l}\text { Heat flux and flow } \\
\text { rate }\end{array}$ & average $h$ improved & [13] \\
\hline \multirow[t]{3}{*}{$\mathrm{Al}_{2} \mathrm{O}_{3}$} & Water & $\begin{array}{l}\text { Rectangular, } \\
\text { Cylinder }\end{array}$ & $0-3 \% \mathrm{VC}$ & Entropy depends on $N u \&$ friction factor & [14] \\
\hline & Water & microchannel & $\operatorname{Re} 100$ to 2300 & Vortex generators provide potential for $h$ & [15] \\
\hline & Water & Rectangular & $\begin{array}{c}\text { Non-uniform mini } \\
\text { baffles }\end{array}$ & Uniform temperature distribution & [16] \\
\hline
\end{tabular}

\section{FUNCTIONALIZATION AND EXPERIMENTAL PROCEDURE}

\subsection{Functionalization of MWCNT nanofluid}

The MWCNT samples were purchased from Nanoshel LLC, USA [26]. The nanotube has a specified diameter of 40-70nm with purity greater than $95 \%$. MWCNT generally do not mix with water due to their hydrophobic nature. In order to obtain a uniform suspension of these nanoparticles, residual metal particles and amorphous carbon are removed by intentionally integrating them with oxygen functional groups. Aggressive oxidative treatments $\left(\mathrm{H}_{2} \mathrm{SO}_{4} / \mathrm{HNO}_{3}\right)$, are necessary to decrease the quantity of amorphous carbon adsorbed on the CNT surface. Following is the method adopted to functionalize MWCNT for their use as nanofluid suspension in water.

$\mathrm{H}_{2} \mathrm{SO}_{4} / \mathrm{HNO}_{3}$ solution in the ratio of $3: 1$ is prepared at a concentration of $20 \%$ each diluting with pure water. Carefully weighed MWCNT are added to the acid solution at $100 \mathrm{mg} / 60 \mathrm{ml}$ of acid solution. The mixed solution was heated and stirred at $100^{\circ} \mathrm{C}$ for 1 hour in a magnetic stirrer. This hot solution was left for cooling for half an hour. The obtained solution is centrifuged with pure water using centrifuge tubes in centrifuge machine and this centrifugation process is carried out till neutral $\mathrm{pH}$ is obtained. The drying process of the solution is carried out in a drying machine at $60^{\circ} \mathrm{C}$ for 24 hours. The nanoparticles obtained after the drying process are the functionalized MWCNT nanoparticles as shown in Figure 1.

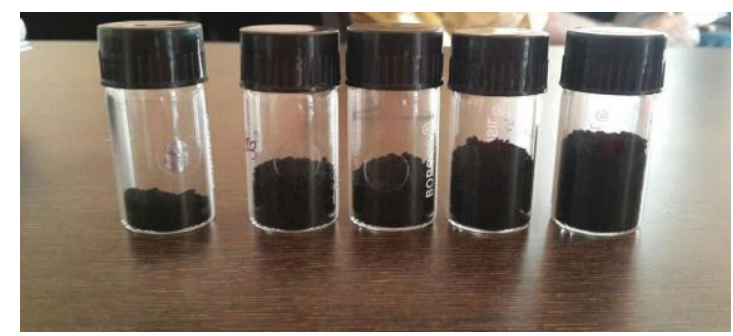

Figure 1. Functionalized MWCNT nanoparticles
To analyze the suspension of MWCNT particles in water after functionalization, Scanning Electron Microscopy (SEM) analysis is carried out. A recommended voltage in order to avoid possible charging effects and achieve better image contrast within the nanotube samples would be 10 and $2 \mathrm{keV}$ (or less) for a field emission SEM.

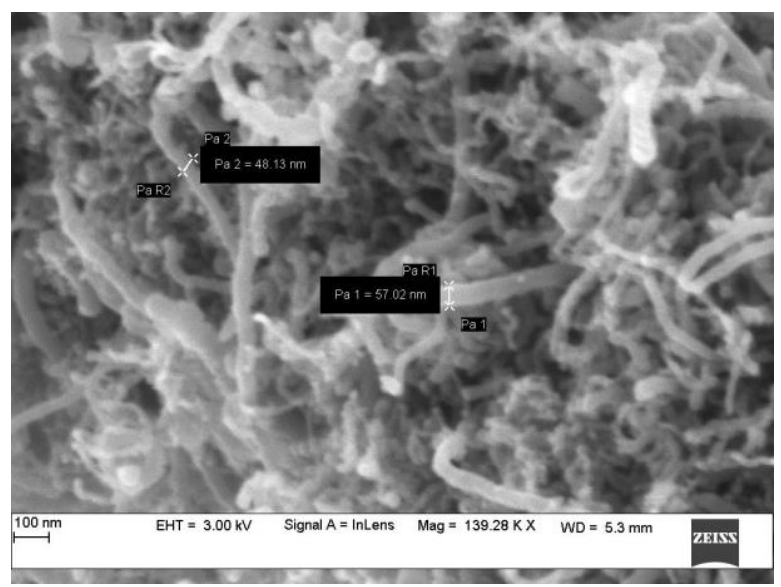

Figure 2. SEM image of CNT before functionalization

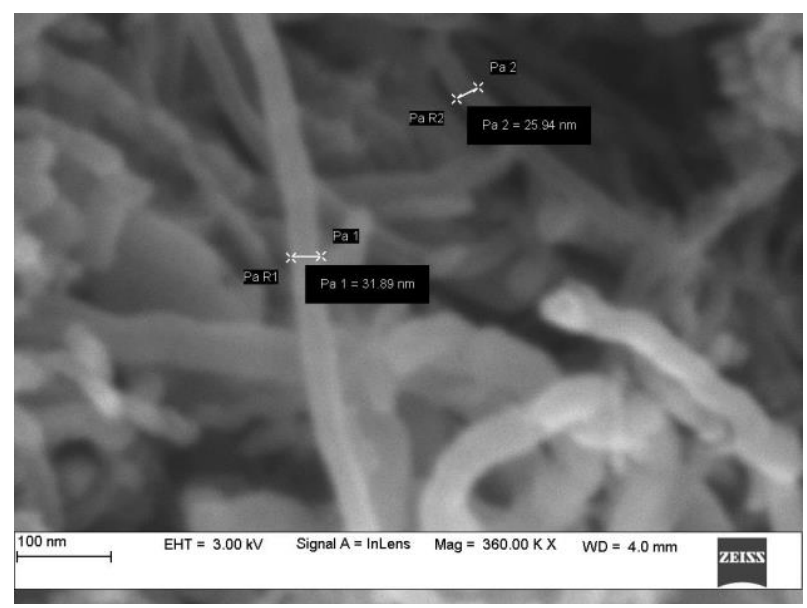

Figure 3. SEM image of CNT after functionalization 
Figure 2 represents SEM image of CNT before functionalization and Figure 3 represents SEM image of CNT after functionalization. On a scale of $100 \mathrm{~nm}$ and at a voltage of $3 \mathrm{KV}$, the average diameter of individual MWCNT was $52 \mathrm{~nm}$ with larger in length of tubes. After functionalization on a same scale and voltage the diameter of the tubes was reduced to an average of $28 \mathrm{~nm}$ and also the length of the tubes was reduced, which is due to the chemical vapour deposition technique (CVD) adopted to oxidize the functional groups. And also due to the purification processes used to remove amorphous carbon and residual metal particle sand as a result of CNT exposure to oxidants present in the environment.

\subsection{Experimental setup}

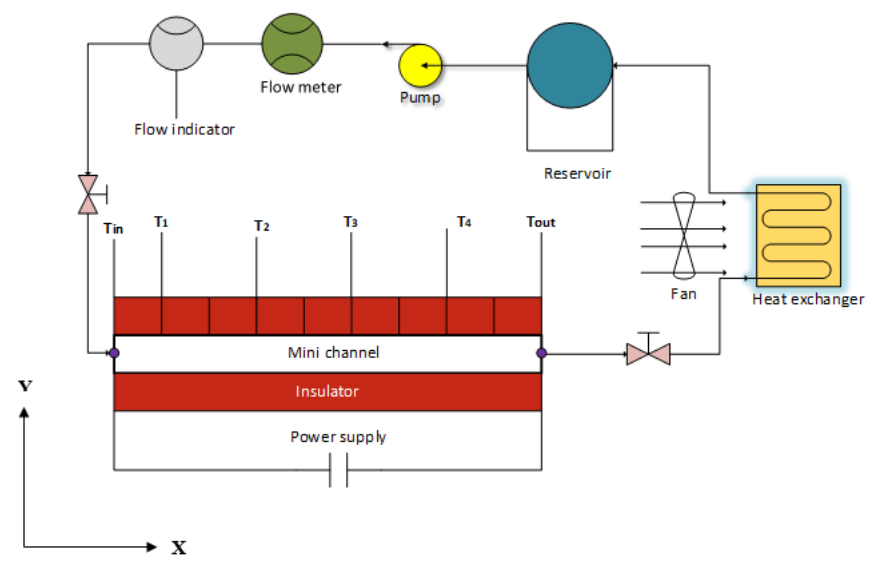

Figure 4. Experimental setup of minichannels

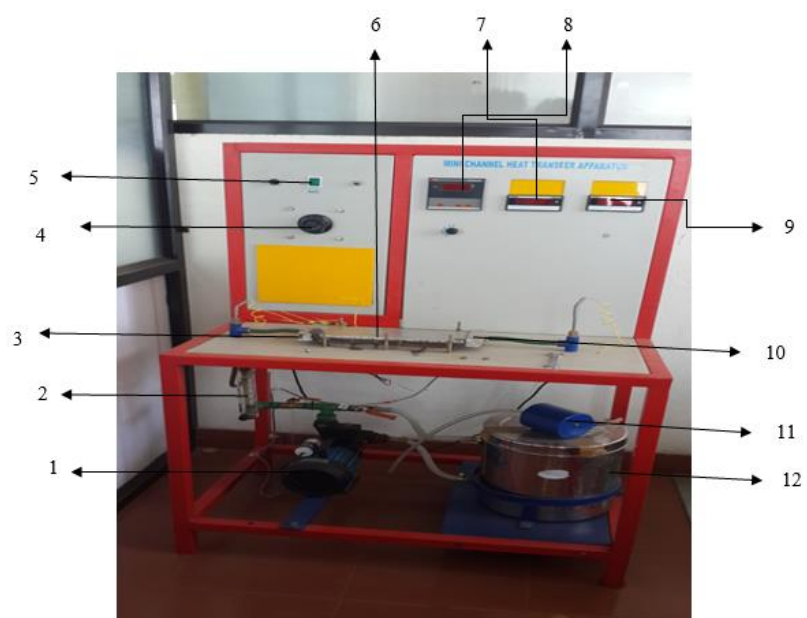

1. Hydraulic Pump, 2. Rotometer, 3. Inlet Port, 4. Dimmer stat, 5. Power Switch, 6. Minichannel, 7. Voltmeter, 8. Temperature Indicator, 9. Ammeter, 10. Outlet Port, 11. Heat Exchanger, 12. Reservoir

Figure 5. Experimental setup photograph

Figure 4 and 5 elucidate the various parts of experimental setup of minichannel heat sink used in the present investigation. The flow rate of flowing fluid in minichannels is measured with efficient and accurate rotometer device. The minichannels is having inlet and outlet ports where the temperature of flowing nanofluids is measured with the help of T-type thermocouples having a sensitivity of $43 \mu \mathrm{V} /{ }^{\circ} \mathrm{C}$ and can measure the temperature in the range of $-220^{\circ} \mathrm{C}$ to $330{ }^{\circ} \mathrm{C}$. Numbers of K-type thermocouples are fixed on the exterior surface of the minichannels to measure the surface temperature at regular intervals along the length of the channel.
K-type thermocouples have range of about $-220^{\circ} \mathrm{C}$ to $1400^{\circ} \mathrm{C}$ and are cheap. An electric film heater is placed beneath the minichannel which transforms alternating current into heat based on the principle of joule heating effect. The heat is first conducted in the walls of minichannels and then transferred to the flowing fluid by convection. To avoid the loss of heat the minichannels is insulated by asbestos. The minichannels is heated with constant heat flux and nanofluid (after sonification process) is made to pass through the minichannels with the help of mini-hydraulic pump till a steady state is reached. When fluid comes out of minichannels further it is made to pass through the heat exchanger where the temperature of fluid drops to ambient temperature. The same cycle is repeated for number of times to achieve the most desirable readings. The rectangular minichannels (length $=300 \mathrm{~mm}$, width $=50 \mathrm{~mm}$ ) are made up of split aluminium plates each channel is of hydraulic diameter of $2 \mathrm{~mm}$.

\subsection{Experimental uncertainty}

\begin{tabular}{|c|c|c|c|}
\hline $\begin{array}{c}\text { Sl } \\
\text { No\# }\end{array}$ & $\begin{array}{c}\text { Measuring } \\
\text { Device }\end{array}$ & Variable & Uncertainty \\
\hline 01 & $\begin{array}{c}\text { K-Type } \\
\text { Thermocouple }\end{array}$ & Temperature $\left({ }^{\circ} \mathrm{C}\right)$ & $\pm 1^{\circ} \mathrm{C}$ \\
\hline 02 & $\begin{array}{c}\text { T-Type } \\
\text { Thermocouple }\end{array}$ & Temperature $\left({ }^{\circ} \mathrm{C}\right)$ & $\pm 0.5^{\circ} \mathrm{C}$ \\
\hline 03 & Flow meter & Flow rate $(\mathrm{lpm})$ & $\pm 0.01 \mathrm{lpm}$ \\
\hline 04 & $\begin{array}{c}\text { Electric film } \\
\text { heater }\end{array}$ & Heat flux $\left(\mathrm{W} / \mathrm{m}^{20} \mathrm{C}\right)$ & $\begin{array}{c} \pm 0.1 \mathrm{~W} / \\
\mathrm{m}^{2 \circ} \mathrm{C}\end{array}$ \\
\hline 05 & Voltmeter & Voltage $($ Volts $)$ & \pm 0.1 volt \\
\hline 06 & Ammeter & Current $($ Ampere $)$ & $\begin{array}{c} \pm 0.1 \\
\text { ampere }\end{array}$ \\
\hline 07 & $\begin{array}{c}\text { Hydraulic mini } \\
\text { Pump }\end{array}$ & $\begin{array}{c}\text { Pumping } \\
\text { Power(Watts })\end{array}$ & $\pm 0.05 \%$ \\
\hline
\end{tabular}

\subsubsection{Methods used to reduce the experimental errors}

a) Instrumental Uncertainty:

Every instrument has got the precision of measurement. The measuring instruments used in the present experimental setup are calibrated by using calibration tool in mechanical measurement and metrology lab under the supervision of highly skillful person. Each calibration procedure for each instrument is repeated for 8-10 times. After confirming the complete calibration, the instruments are used in the experimental setup.

b) Random Uncertainty:

There are certain uncontrolled factors which may affect the value of measurement each time we take readings and such uncertainty is called as random uncertainty. To avoid such random uncertainty in the present investigation each set of reading is repeated for 10 times and after achieving certainty in readings the final data is taken.

\subsection{Relations used}

The following Equations 1-8 were used to estimate the different important thermal parameters of the minichannel heat sink [31-33].

Actual heat transfer: $\quad q=m_{f} C_{p}\left(T_{c, o}-T_{c, i}\right)$

Reynolds number: $\quad R_{e}=\rho D_{h} v / \mu$ 


$$
\text { LMTD : } \quad \Delta T_{l m t d}=\left(\Delta T_{2}-\Delta T_{1}\right) / \ln \left(\frac{\Delta T_{2}}{\Delta T_{1}}\right)
$$$$
\text { Where } \quad \Delta T_{2}=\Delta T_{b}-\Delta T_{h, o}, \Delta T_{1}=\Delta T_{b}-\Delta T_{c, i}
$$$$
\text { Nusselt number: } N u=0.027 \operatorname{Re}^{0.8} \operatorname{Pr}^{0.33}\left(\frac{\mu}{\mu_{w}}\right)^{0.14}
$$

Heat transfer coefficient: $h=N_{u} k / D_{h}$

Friction factor:

$$
f=0.184 R e^{-0.2}
$$

$$
\text { Pressure drop: } \quad \Delta P=f \rho(L / D)\left(v^{2} / 2\right)
$$

Pumping power: $P=\Delta P f v$

\section{RESULTS AND DISCUSSIONS}

Volume concentration of $0.01 \%$ of MWCNT nanoparticles is used in this case, and for three flow rates of $0.251 \mathrm{pm}, 0.51 \mathrm{pm}$ and $0.751 \mathrm{pm}$ the values of temperature is recorded after reaching a steady state. For each flow rate three trails were taken which consumes at least 3 hours of time. Water was circulated for the same flow rates to compare with the results of MWCNT nanofluid.

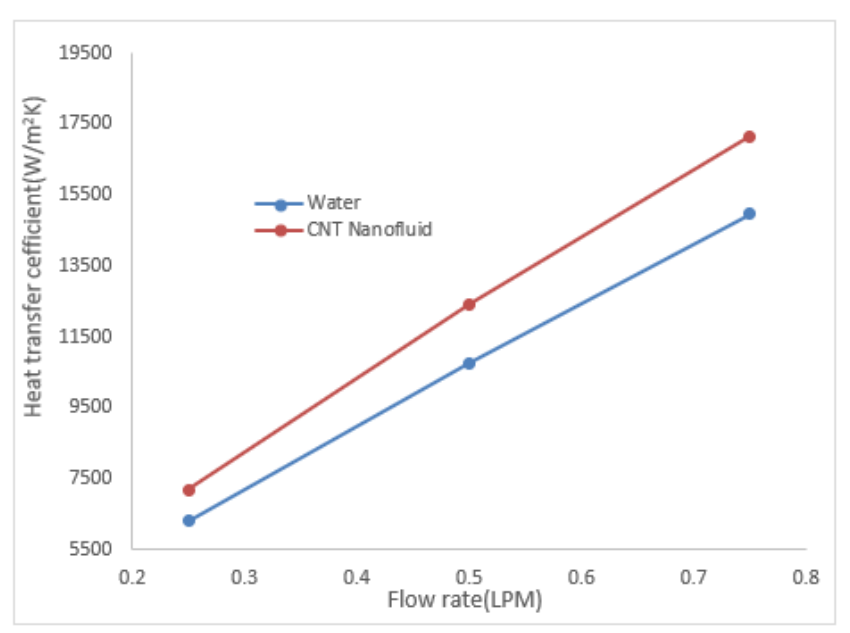

Figure 6. Effect of flow rate on heat transfer coefficient

Figure 6 illustrates the effect of flow rates on heat transfer coefficient when water and CNT were used as flowing fluids. It is clearly observed from the Figure that with increase in the flow rate of both the fluids the heat transfer coefficient also increases as this may be due to increase in the velocity of flowing fluid. It is also observed that compare to water the CNT nanofluids results in enhancement of heat transfer coefficient though the flow rate for both the fluid is same. This may be due to high thermal conductivity of CNT nanofluid which may leads to carry more amount of heat hence further increasing the convective heat transfer coefficient of fluid. A maximum difference in heat transfer coefficient of both the fluids is observed at a flow rate of $0.751 \mathrm{pm}$. It is also observed that with further increase in flow rates, increase in the heat transfer coefficient was less.

The Figure 7 shows the variation of Nusselt number with flow rate for both CNT and water at fully developed flow condition. As the flow rate increase the Nusselt number also increases which is due to increase in heat transfer coefficient.
The Nusselt number for water is maximum when compared to CNT nanofluid because of high thermal conductivity of the CNT nanofluid which is inversely proportional to the Nusselt number.

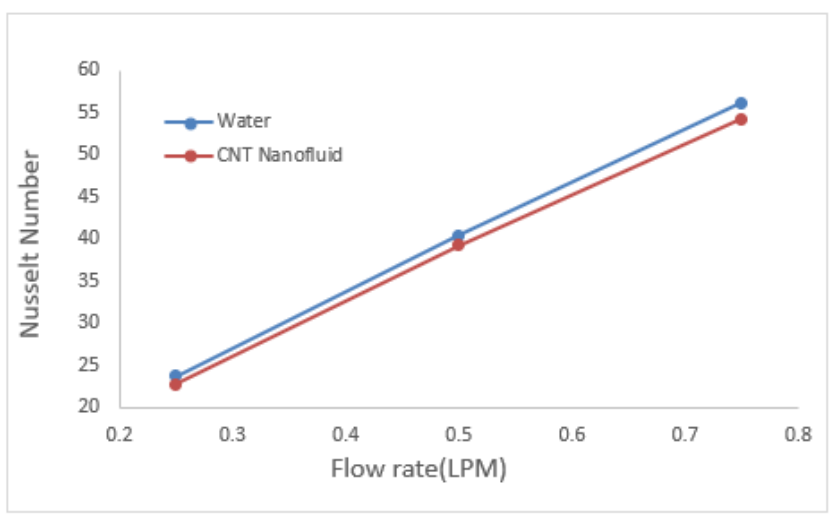

Figure 7. Effect of flow rate on Nusselt number

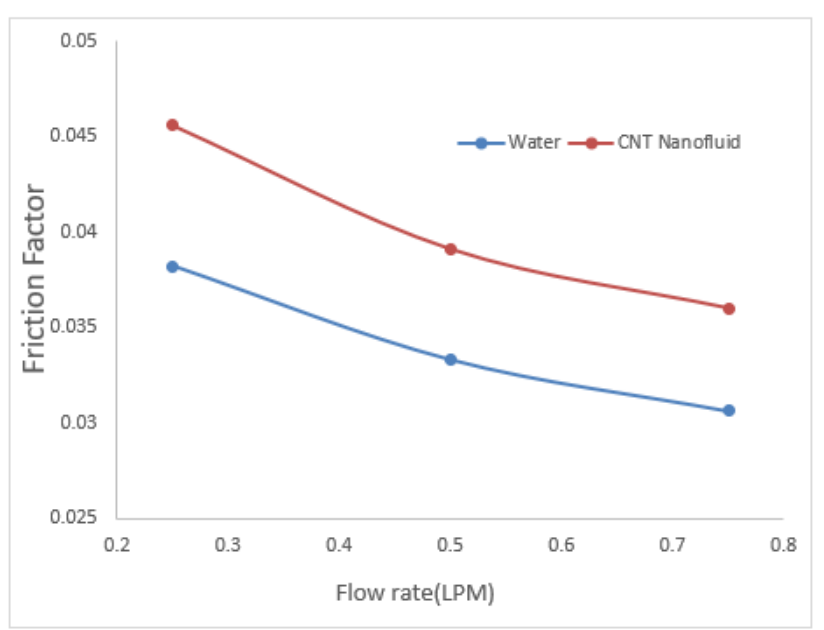

Figure 8. Effect of flow rate on friction factor

Figure 8 depicts the impact of flow rate on friction factor for CNT nanofluid and water. It is observed that when flow rate increases the friction factor decreases irrespective of flowing fluid. As the fluid rushes into the channel with high velocity which may leads to decrease the friction between the fluid layer and walls of the channel. This decrease in the friction value increases with increase in flow rate. But it is also observed that for CNT nanofluids the friction between the fluid layer and walls of the channel is more as it can be observed from Figure 8. As the presence of nanoparticles may lead to create more viscous force on the walls of channel, which is due to increase in viscosity of nanofluid. Though the concentration of nanoparticle is less but some of the nanoparticles may get adhere to the walls of channel which may create more disturbance leading to increase the friction between the walls of channel and flowing fluid.

Figure 9 illustrate the effect of flow rate on pressure drop along the length of the channel. It is observed that in case of CNT nanofluid the pressure drop is more compare to water this increase in the rate of pressure drop is mainly due to suspension of nanoparticles in a fluid. The nanoparticles increase the viscous force in the fluid and this increase in the viscous force may lead to increase the friction between walls of the channel and fluid and hence further leads to increase the 
pressure drop. One more thing to be observed from Figure 9 is that with increase in flow rate the pressure drop also increases this may be due to increase in the velocity of flowing fluid which may additionally affect the pressure of flowing fluid.

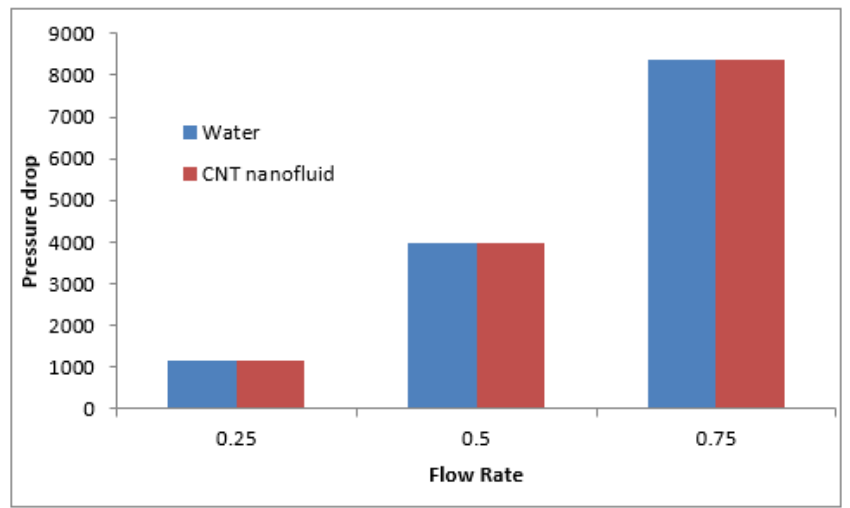

Figure 9. Effect of Flow rate on pressure drop

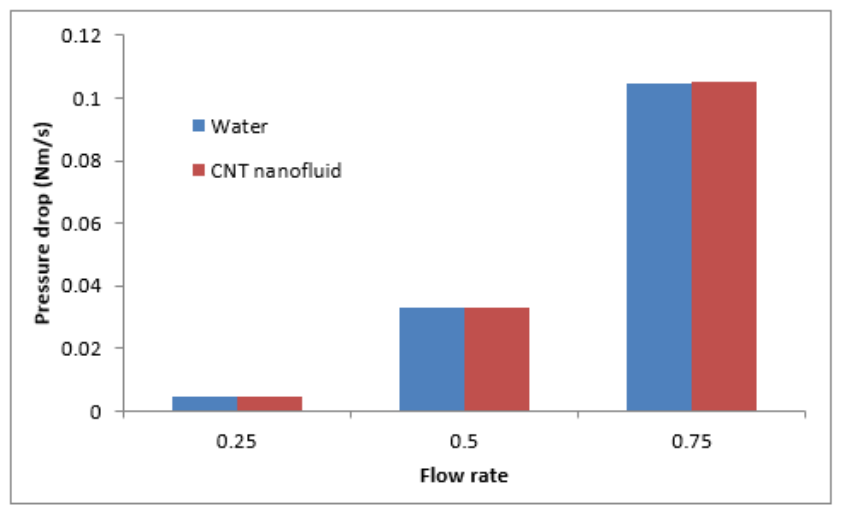

Figure 10. Effect of flow rate on pumping power

The Figure 10 depicts the change in pumping power with flow rate. It is clearly seen that with increase in flow rate the pumping power also increases, and it is known fact that the velocity and pressure are inversely proportional to each other in a flowing fluid which leads to overall drop of pressure throughout the length of the channel. Pressure drop and pumping power for both the fluids is slightly different as the volume concentration of nanoparticles in water is very less.

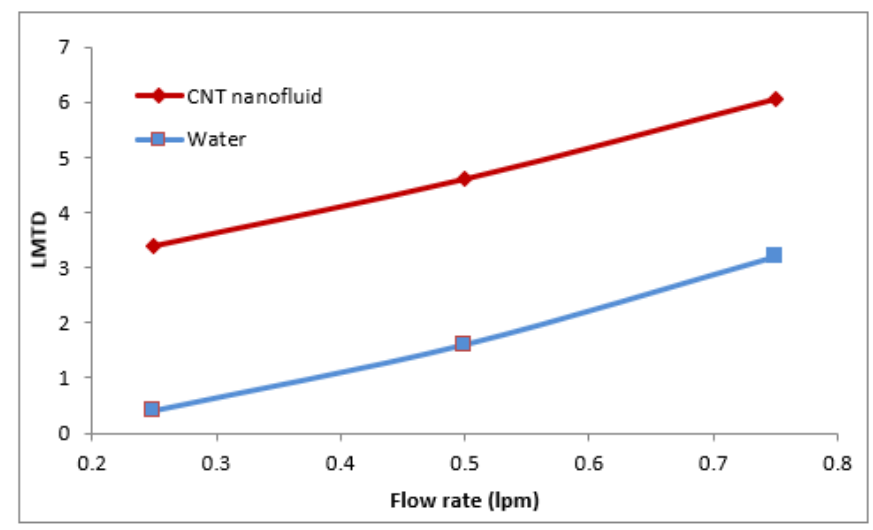

Figure 11. Effect of flow rate of LMTD

Figure 11 elucidate the effect of flow rate of both CNT nanofluid and water on LMTD. It is clear from the Figure that with increase in the flow rate of fluids the LMTD also increases and the difference by which LMTD increases for both the fluids remains almost constant throughout the different flow rates. For CNT nanofluids the LMTD value is more compare to water this may be due to suspension of multiwalled carbon nano tube particles in base fluid which may tend to increase and improve the heat conducting ability of fluid which may further leads to enhance the heat transfer capability of fluid and hence results in achieving the better LMTD range.

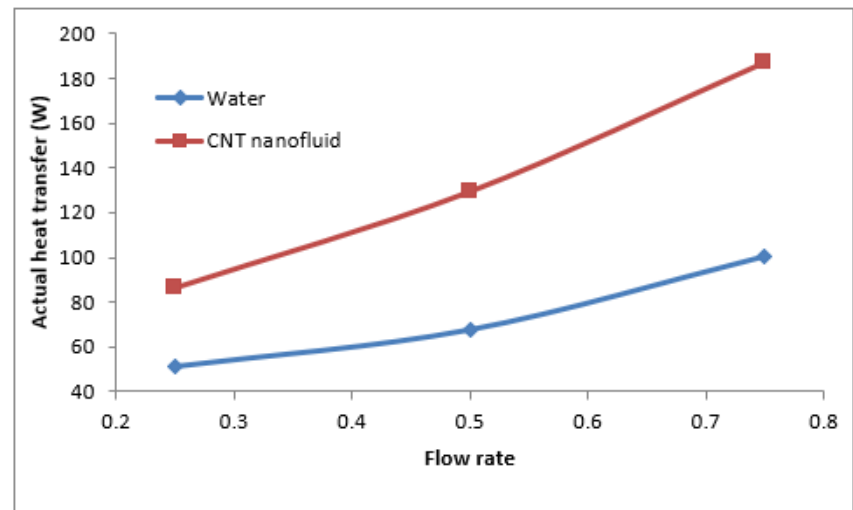

Figure 12. Flow rate vs Actual heat transfer

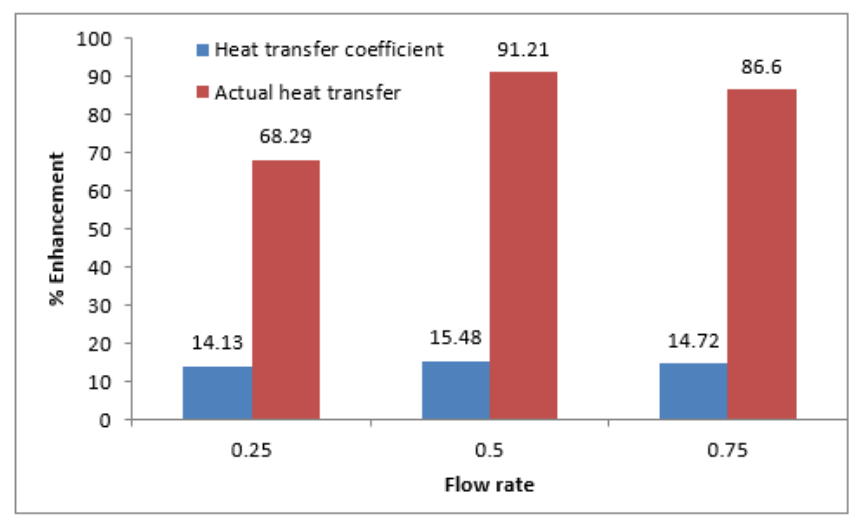

Figure 13. \% Enhancement in heat transfer characters for different flow rates

In Figure 12 and 13, variation of actual heat transfer and its \% enhancement for different flow rates of MWCNT nanofluid compared to water is shown. Clearly it can be noted that, actual heat transfer is more for all flow rates for MWCNT nanofluid compared to water which is due to its enhanced specific heat capacity. Percentage enhancement for actual heat transfer and convective heat transfer coefficient compared to water is seen in Figure 13. For all flow rates, percentage enhancement is seen for the nanofluid, but for $0.5 \mathrm{lpm}$ the percentage increase is maximum compared to water.

\section{CONCLUSION}

An experimental study has been carried out on comparative heat transfer analysis of rectangular minichannels subjected to MWCNT and pure water as a fluid. The experiments were conducted for constant heat flux steady state turbulent forced flow conditions. During the time of experiments the following concluding remarks were disclosed.

- With increase in the flow rate the convective heat 
transfer coefficient increases, and it is maximum in case of MWCNT nanofluid compare to water.

- $\quad$ For MWCNT nanofluid the amount of pumping work required is more compared to water.

- $\quad$ Even small percentage of MWCNT nanoparticles suspension in base fluid can improve and enhance the heat transfer capability of fluid.

- There exists an upper limiting value of flow rate $(0.5 \mathrm{lpm})$ beyond which increase in heat transfer coefficient may not get affected.

- $\quad$ Finally it may be concluded that MWCNT with low volume concentration proves to be a better heat transfer fluid but at the cost of pumping power.

\section{REFERENCES}

[1] Sohel M, Khaleduzzaman S, Saidur R. (2014). An experimental investigation of heat transfer enhancement of a minichannel heat sink using $\mathrm{Al}_{2} \mathrm{O}_{3}-\mathrm{H}_{2} \mathrm{O}$ nanofluid. Int. J Heat Mass Transf. 74: 164-72.

[2] Ijam A, Saidur R, Ganesan P. (2012). Cooling of minichannel heat sink using nanofluids. Int Commun Heat Mass Transf. 39: 1188-94.

[3] Keshavarz Moraveji M, Mohammadi Ardehali R, Ijam A. (2013). CFD investigation of nanofluid effects (cooling performance and pressure drop) in mini-channel heat sink. Int. Commun. Heat Mass Transf. 40: 58-66. https://doi.org/10.1016/j.icheatmasstransfer.2012.10.02 1.

[4] Xie X, Liu Z, He Y, Tao W. (2009). Numerical study of laminar heat transfer and pressure drop characteristics in a water-cooled minichannel heat sink. Appl. Therm. Eng. 29: 64-74.

[5] Ho CJ, Chen WC. (2013). An experimental study on thermal performance of $\mathrm{Al}_{2} \mathrm{O}_{3}$ /water nanofluid in a minichannel heat sink. Appl Therm Eng. 50: 516-22. https://doi.org/10.1016/j.applthermaleng.2012.07.037.

[6] Dixit T, Ghosh I. (2013). Low Reynolds number thermohydraulic characterization of offset and diamond minichannel metal heat sinks. Exp Therm Fluid Sci 51: 227-38.

https://doi.org/10.1016/j.expthermflusci.2013.08.002.

[7] Yoon SH, Saneie N, Kim YJ. (2014). Two-phase flow maldistribution in minichannel heat-sinks under nonuniform heating. Int J Heat Mass Transf 78: 527-37. https://doi.org/10.1016/j.ijheatmasstransfer.2014.07.013

[8] Fan Y, Lee PS, Jin LW, Chua BW, Zhang DC. (2014). A parametric investigation of heat transfer and friction characteristics in cylindrical oblique fin minichannel heat sink. Int $J$ Heat Mass Transf 68: 567-84. https://doi.org/10.1016/j.ijheatmasstransfer.2013.09.027.

[9] Naphon P, Nakharintr L. (2013). Heat transfer of nanofluids in the mini-rectangular fin heat sinks. Int Commun Heat Mass Transf 40: 25-31. https://doi.org/10.1016/j.icheatmasstransfer.2012.10.01 2.

[10] Sakanova A, Keian CC, Zhao J. (2015). Performance improvements of microchannel heat sink using wavy channel and nanofluids. Int J Heat Mass Transf 89: 5974. 10.1016/j.ijheatmasstransfer.2015.05.033

[11] Zakaria I, Azmi WH, Mamat AMI, Mamat R, Saidur R, Abu Talib SF, et al. (2016). Thermal analysis of $\mathrm{Al}_{2} \mathrm{O}_{3}$ - water ethylene glycol mixture nanofluid for single PEM fuel cell cooling plate: An experimental study. Int J Hydrogen Energy 41: 5096-112.

[12] Kanikzadeh M, Sohankar A. (2016). Thermal performance evaluation of the rotating U-shaped $\mathrm{micro} / \mathrm{mini} / \mathrm{macrochannels} \mathrm{using} \mathrm{water} \mathrm{and} \mathrm{nanofluids.}$ Numer Heat Transf Part A Appl 70: 650-72.

[13] Marzougui M, Nmiri C, Hammami M, Ben MR. (2016). Experimental investigation of heat transfer characteristics and cooling performance of mini- and microheat exchangers. Heat Transf Res 1-17.

[14] Li P, Xie Y, Zhang D, Xie G. (2016). Heat transfer enhancement and entropy generation of nanofluids laminar convection in microchannels with flow control devices. Entropy 18. https://doi.org/10.3390/e18040134.

[15] Al-Asadi MT, Alkasmoul FS, Wilson MCT. (2016). Heat transfer enhancement in a micro-channel cooling system using cylindrical vortex generators. Int Commun Heat Mass Transf 74: 40-47. https://doi.org/10.1016/j.icheatmasstransfer.2016.03.00 2.

[16] Liu X, Yu J. (2016). Numerical study on performances of mini-channel heat sinks with non-uniform inlets. Appl Therm Eng 93: 856-64.

[17] Huminicn G, Huminic A. (2016). Application of nanofluids in heat exchangers: A review. Renew Sustain Energy Rev 16: 5625-38.

[18] Afzal A, Samee ADM, Razak RKA. (2017). Experimental thermal investigation of $\mathrm{CuO}-\mathrm{W}$ nanofluid in circular minichannel. Model Meas Control B 86: 33544.

[19] Ismail M, Fotowat S, Fartaj A. (2016). Numerical simulation of $\mathrm{Al}_{2} \mathrm{O}_{3}$ /automatic transmission fluid and $\mathrm{Al}_{2} \mathrm{O}_{3}$ /water nanofluids in a compact heat exchanger. $\mathrm{J}$ Fluid Flow, Heat Mass Transf 3: 34-43.

[20] Betz AR, Attinger D. (2010). Can segmented flow enhance heat transfer in microchannel heat sinks? Int J Heat Mass Transf 53: 3683-91.

[21] Kumaresan V, Velraj R. (2012). Thermochimica Acta Experimental investigation of the thermo-physical properties of water - ethylene glycol mixture based CNT nanofluids. Thermochim Acta 545: 180-6.

[22] Ahammed N, Asirvatham LG, Wongwises S. (2016). Thermoelectric cooling of electronic devices with nanofluid in a multiport minichannel heat exchanger. Exp Therm Fluid Sci 74: 81-90.

[23] Ahrara A, Djavareshkianb M, Ataiyanc M. (2017). Numerical simulation of $\mathrm{Cu}$-water nanofluid magnetohydro-dynamics and heat transfer in a cavity containing a circular cylinder of different size and positions. Int $\mathbf{J}$ Heat Technol 35: 403-15.

[24] Rashad AM. (2017). Unsteady nanofluid flow over an inclined stretching surface with convective boundary condition and anisotropic slip impact. Int J Heat Technol 35: 82-90. https://doi.org/10.18280/ijht.350111.

[25] Afzal A, Nawfal I, Mahbubul IM, Kumbar SS. (2018). An overview on the effect of ultrasonication duration on different properties of nanofluids. J Therm Anal Calorim. https://doi.org/10.1007/s10973-018-7144-8.

[26] Kumar M, Afzal A, Ramis MK. (2017). Investigation of physicochemical and tribological properties of $\mathrm{TiO} 2$ nano-lubricant oil of different concentrations. TribolFinnish J Tribol 35: 6-15.

[27] Leela Vinodhan V, Suganthi KS, Rajan KS. (2016). 
Convective heat transfer performance of $\mathrm{CuO}$-water nanofluids in U-shaped minitube: Potential for improved energy recovery. Energy Convers Manag 118: 415-425. https://doi.org/10.1016/j.enconman.2016.04.017.

[28] Yang C, Peng K, Nakayama A, Qiu T. (2016). Forced convective transport of alumina-water nanofluid in micro-channels subject to constant heat flux. Chem Eng Sci 152: 311-22.

[29] Vafaei S, Wen D. (2012). Convective heat transfer of aqueous alumina nanosuspensions in a horizontal minichannel. Heat Mass Transf Und Stoffuebertragung 48: 349-57.

[30] Savari M, Rashidi S, Amiri A, Shanbedi M, Zeinali Heris S, Kazi SN. (2016). Hydrodynamic and thermal performance prediction of functionalized MWNT-based water nanofluids under the laminar flow regime using the adaptive neuro-fuzzy inference system. Numer Heat Transf Part A Appl 70: 103-16.

[31] Sohel MR, Saidur R, Khaleduzzaman SS, Ibrahim TA. (2015). Cooling performance investigation of electronics cooling system using $\mathrm{Al}_{2} \mathrm{O}_{3}-\mathrm{H}_{2} \mathrm{O}$ nanofluid. Int Commun Heat Mass Transf 65: 89-93.

[32] Khaleduzzaman SS, Sohel MR, Mahbubul IM, Saidur R, Selvaraj J. (2016). Exergy and entropy generation analysis of $\mathrm{TiO}_{2}$-water nanofluid flow through the water block as an electronics device. Int J Heat Mass Transf 101: 104-11.

[33] Afzal A, Samee ADM, Javad A, Shafvan SA, PVA, Kabeer KMA. (2017). Heat transfer analysis of plain and dimpled tubes with different spacings. Heat Trans Asian Res. 1-13. https://doi.org/10.1002/htj.21318

\section{NOMENCLATURE}

$\begin{array}{ll}R e & \text { Reynolds number } \\ N u & \text { Nusselt number } \\ v & \text { Fluid average velocity } \mathrm{m} / \mathrm{s} \\ h & \text { Convective heat transfer coefficient, } \mathrm{W} / \mathrm{m}^{2} \\ & \mathrm{~K} \\ k & \text { Thermal conductivity, W/m K } \\ D_{h} & \text { Hydraulic diameter, } \mathrm{m} \\ T & \text { Temperature, }{ }^{\circ} \mathrm{C} \\ b, w & \text { base, water } \\ L M T D & \text { Log Mean Temperature Difference } \\ L & \text { Length of the channel, } \mathrm{m} \\ P r & \text { Prandtl number } \\ \% & \text { Percentage } \\ \mu & \text { Viscosity }\end{array}$

